\title{
COMPARAÇÃO DO CALCÁRIO LÍQUIDO COM O CALCÁRIO EM PÓ NA FERTILIDADE DO SOLO E NUTRIÇÃO DO FEIJOEIRO
}

Fernando Shintate Galindo ${ }^{1 *}$, Juliano Costa da Silva ${ }^{1}$, Gustavo Antonio Xavier Gerlach ${ }^{1}$, Marina Munhoz Rosato Ferreira ${ }^{2}$, Adriana de Souza Colombo ${ }^{3}$, Marcelo Carvalho Minhoto Teixeira Filho ${ }^{4}$

\footnotetext{
${ }^{1}$ Doutorando em Agronomia - Sistemas de Produção - Universidade Estadual Paulista (UNESP), Faculdade de Engenharia, Câmpus de Ilha Solteira - SP. *Email do autor correspondente: fs.galindo@ yahoo.com.br

${ }^{2}$ Mestre em Agronomia - Sistemas de Produção - Universidade Estadual Paulista (UNESP), Faculdade de Engenharia, Câmpus de Ilha Solteira - SP.

${ }^{3}$ Professora do curso de Tecnologia em Agronegócio - Faculdade de Tecnologia de Jales (FATEC) - Jales -SP

${ }^{4}$ Professor do Departamento de Fitossanidade, Engenharia Rural e Solos - Universidade Estadual Paulista (UNESP), Faculdade de Engenharia, Câmpus de Ilha Solteira - SP.
}

RESUMO: O calcário em pó é o corretivo de acidez do solo mais utilizado no Brasil. Contudo, novos produtos vêm sendo testados para melhorar o condicionamento do solo, entre eles, o calcário líquido, que é um produto em suspensão com nano-partículas e vendido como produto de eficiência aprimorada. Como são escassos os trabalhos que relatam os efeitos do calcário líquido em comparação com outros corretivos, objetivou-se avaliar o efeito da aplicação de doses e fontes de calcário nos atributos químicos do solo e nos teores de nutrientes da parte aérea e raiz do feijoeiro, cultivado em Latossolo Vermelho distroférrico. O delineamento experimental foi em blocos ao acaso, com quatro blocos e em esquema fatorial $4 \times 2$, constituídos de quatro doses de calcário (zero, 1/2; 1 e $2 \times$ a dose de referência) e dois tipos de calcários (calcário em pó e calcário líquido). O calcário em pó propiciou menor acidez potencial e maiores concentrações de $\mathrm{Ca}, \mathrm{Mg}, \mathrm{SB}, \mathrm{CTC}, \mathrm{V} \%$ e $\mathrm{pH}$, indicando que o calcário líquido não foi eficaz na correção da acidez do solo e fornecimento de $\mathrm{Ca}$ e $\mathrm{Mg}$. As fontes de calcário proporcionaram semelhantes teores de macro e micronutrientes na parte aérea e na raiz do feijoeiro irrigado. O incremento das doses de calcário não influenciou os teores de nutrientes no feijoeiro em função da fertilidade inicial do solo.

Palavras-chave: Phaseolus vulgaris L. Corretivo líquido. Calagem. Corretivos de acidez do solo. Diagnose nutricional.

\section{COMPARISON OF LIQUID LIMESTONE WITH POWDER LIMESTONE IN SOIL FERTILITY AND NUTRITION OF COMMON BEAN}

\begin{abstract}
The limestone powder is used as soil acidity corrective in Brazil. However, new products have been tested to improve the conditioning of soil, among them, the liquid limestone, which is a product in suspension with nano-particles and sold as a product of improved efficiency. As there are few studies reporting the effects of liquid lime compared to other correctives, aimed to evaluate the effect of application of doses and sources of soil
\end{abstract} Cultura Agronômica, Ilha Solteira, v.26, n.3, p.265-284, 2017 
correctives on the soil chemical attributes and nutritents contents of shoots and root common bean, grown in Oxisol dystroferric. The experimental design was a randomized block with four blocks and a 4x2, being four limestone rates (zero, 1/2, 1 and $2 x$ the reference dose) and two types of soil correctives (limestone powder and corrective fluid acidity). The limestone powder showed lower potential acidity and higher concentrations of $\mathrm{Ca}, \mathrm{Mg}, \mathrm{SB}, \mathrm{CEC}, \mathrm{V} \%$ and $\mathrm{pH}$, indicating that the liquid lime was not effective in correcting soil acidity and supply of $\mathrm{Ca}$ and $\mathrm{Mg}$. The sources of correctives provided similar macro and micronutrients contents in the shoot and root of irrigated common bean. The increase in corrective doses did not affect the nutrients contents in the common bean in function of the initial soil fertility.

Key words: Phaseolus vulgaris L. Fluid lime. Liming. Soil acidity correction. Nutritional diagnosis.

\section{INTRODUÇÃO}

O feijão (Phaseolus vulgaris L.) é muito importante para a alimentação da população brasileira, sendo cultivado praticamente em todo o país, constituindo-se em uma das principais fontes de proteína para as populações de baixa renda, e apresenta ainda, como vantagem, a possibilidade de cultivo em três diferentes épocas do ano, definidos como, cultivos "das águas", "da seca" e "de inverno" (BINOTTI et al., 2010). Contudo, os solos agrícolas brasileiros, em especial os Latossolos, por serem altamente intemperizados apresentam média a alta acidez, o que traz como consequência, a baixa produtividade das culturas, em decorrência da toxidez causada por alumínio $(\mathrm{Al})$ e manganês $(\mathrm{Mn})$, deficiência de fósforo (P) e pela baixa saturação por bases (V\%) (CALONEGO et al., 2012; NÓIA et al., 2014).

A acidez do solo é um dos fatores que mais limitam a produtividade das culturas em várias partes do mundo, inclusive no Brasil. Nos solos ácidos existem problemas de deficiência e/ou toxidez nutricional, baixa capacidade de retenção de água e baixa atividade dos microrganismos. Os solos de cerrado, com essas características, apresentam baixa produtividade em estado natural. Para incorporação desses solos ao processo produtivo é indispensável o uso adequado de corretivos, como calcário e adubação. A calagem ainda é uma das práticas menos dispendiosas e efetivas na correção da acidez do solo, embora se constitua na maneira mais fácil e barata de elevar o $\mathrm{pH}$ do solo (NICOLODI et al., 2008; SOUZA et al., 2011).

O principal efeito da calagem decorre na neutralização de alumínio e manganês, além de fornecer cálcio e magnésio como nutrientes, aumentar a disponibilidade do fósforo, favorecer a mineralização da matéria orgânica e apresentar efeito positivo na fixação simbiótica do nitrogênio. As propriedades físicas também são favorecidas pela calagem, em função da adição dos cátions floculantes aos colóides do solo, cálcio e magnésio, e desta maneira, por estimular sistemas radiculares mais extensos, aumenta a absorção de água e

Cultura Agronômica, Ilha Solteira, v.26, n.3, p.265-284, 2017 
nutrientes no solo (LEITE et al., 2006; RAIJ, 2010), entretanto, a calagem diminui a disponibilidade dos micronutrientes catiônicos.

A aplicação de corretivos de acidez de solo tem apresentado resultados positivos ao longo dos anos nos atributos químicos do solo, desenvolvimento do sistema radicular, da parte aérea, bem como na produtividade do feijoeiro (BARBOSA FILHO et al., 2005; SILVA et al., 2007a), além de aumentos na matéria seca radicular e matéria seca da parte aérea da cultura (SILVA et al., 2007b; SILVA et al., 2012).Um sistema radicular pouco desenvolvido prejudica a absorção de água, nutriente e, consequentemente, produtividade das culturas. As limitações impostas pela acidez do solo podem ser solucionadas mediante a união dos esforços das áreas de melhoramento de plantas e de manejo do solo, e sendo o feijoeiro uma cultura sensível à acidez (RANGEL et al., 2009), a calagem tem sido prática indispensável para viabilizar o seu cultivo.

Contudo, o calcário necessita de tempo para reagir adequadamente no solo, e o ideal seria a sua incorporação ao solo, porém nem sempre é possível, ou seja, para que ocorra a reação em profundidade é necessário que o calcário se mova para camadas mais profundas, o que acarreta demora na reação do corretivo no solo (CHURKA BLUM et al., 2013). Entretanto, pesquisas estão em andamento visando o desenvolvimento de novos produtos, e dentre estes destacam-se o carbonato de cálcio moído com partículas na granulometria nanométrica, como o recém-lançado calcário líquido (ASSIS et al., 2014; NASCENTE; COBUCCI, 2015). As principais vantagens do calcário líquido de acordo com os fabricantes são: o fácil manuseio e aplicação; bons teores de Ca e $\mathrm{Mg}$; não necessita incorporação no solo, apenas irrigação ou chuva; proporciona condições no solo para o aumento da eficiência dos fertilizantes aplicados; cria condições favoráveis para o aumento de produtividade das plantas.

Pesquisas com o uso de calcário líquido são muito escassas no Brasil, portanto, é necessário averiguar se realmente os calcários líquidos são eficazes na correção da acidez do solo e seu reflexo na nutrição de plantas. Em estudo com aplicação no sulco de semeadura de calcário na forma líquida na cultura do feijoeiro, Nascente e Cobucci (2015), concluíram que a aplicação de solução de micropartículas de $\mathrm{CaCO}_{3}$ causa ligeiro aumento localizado, dos valores de $\mathrm{pH}$, e redução da saturação de $\mathrm{Al}$ no solo, além de proporcionar incrementos significativos do número de vagens por área e da produtividade de grãos do feijoeirocomum. Com base no exposto, objetivou-se avaliar o efeito da aplicação de doses e fontes de calcário nos atributos químicos do solo e nos teores de nutrientes da parte aérea e raiz do feijoeiro, cultivado em Latossolo Vermelho distroférrico.

\section{MATERIAL E MÉTODOS}

A pesquisa foi realizada em casa de vegetação com sombrite de 50\%, no Departamento de Fitossanidade, Engenharia Rural e Solos, da Faculdade de Engenharia de Ilha Solteira - Unesp, Campus de Ilha Solteira, SP (20²5’ S, 51²0’ W; $376 \mathrm{~m}$ de altitude),

Cultura Agronômica, Ilha Solteira, v.26, n.3, p.265-284, 2017 
no período compreendido entre os meses de setembro a dezembro de 2014. A cultura implantada foi a do feijão (Phaseolus vulgaris L.), do grupo carioca cv. IPR Tangará, que possui hábito de crescimento indeterminado, porte ereto e ciclo de aproximadamente 87 dias.

O solo utilizado no experimento foi um Latossolo Vermelho Distroférrico, textura argilosa, segundo a Embrapa (2013), da camada de 0-20 cm de profundidade, o qual foi cultivado por culturas anuais há mais de 27 anos, sendo os últimos 10 anos em sistema plantio direto, sendo o trigo a cultura utilizada anteriormente.

Para o experimento em condições controladas foram efetuadas análises químicas do solo, anteriormente a aplicação dos tratamentos, e 62 dias após a aplicação seguindo as recomendações de Raij et al. (2001), apresentando os seguintes resultados: 39, 13, 0,18, 10,8 e $39 \mathrm{mg} \mathrm{dm}^{-3}$ de P, S, B, Cu e Fe, respectivamente, $29 \mathrm{~g} \mathrm{dm}^{-3}$ de M.O., 4,4, 36, 22, $62,4,94,4 \mathrm{mmol}_{\mathrm{c}} \mathrm{dm}^{-3}$ de $\mathrm{K}, \mathrm{Ca}, \mathrm{Mg}, \mathrm{SB}$ e CTC, respectivamente e 66 de V\%.

O delineamento experimental utilizado foi em blocos casualizados, com quatro repetições e em esquema fatorial $4 \times 2$, constituído por quatro doses de calcário: zero (testemunha), 1/2; 1 e 2x a dose recomendada e dois tipos de calcário (calcário dolomítico em pó e calcário líquido). A unidade experimental foi composta por um vaso com uma planta de feijão. A dose de referência para elevar a saturação por bases a $90 \%$ foi equivalente a $2,57 \mathrm{t} \mathrm{ha}^{-1}$ de calcário em pó como a dose de referência representa $1250 \mathrm{mg}$ $\mathrm{dm}^{-3}$, aplicou-se $8750 \mathrm{mg}$ de calcário por vaso com capacidade de $7 \mathrm{dm}^{3}$ de solo. A dose de calcário líquido utilizada foi a indicada pelo fabricante, sendo $5 \mathrm{~L}$ do produto comercial por tonelada de calcário em pó recomendado para aplicação, sendo aplicados 0,04375 mL por vaso com $7 \mathrm{dm}^{3}$ de solo.

O calcário dolomítico em pó apresentava $88 \%$ de PRNT, 28\% de $\mathrm{CaO}$ e $12 \%$ de $\mathrm{MgO}$. $\mathrm{O}$ calcário líquido utilizado apresentava garantias de $23 \%$ de $\mathrm{CaO}, 18,2 \%$ de $\mathrm{MgO}$, densidade $1,8 \mathrm{~kg} \mathrm{~L}^{-1}, 16,5 \%$ de $\mathrm{Ca}, 11 \%$ de $\mathrm{Mg}$ e $46,7 \%$ de $\mathrm{CaCO}_{3}$.

O solo foi peneirado em malha de $4 \mathrm{~mm}$, seco ao ar e posteriormente acondicionado em sacos plásticos. As doses de calcário foram aplicadas nos sacos plásticos e incorporadas ao solo de forma manual. Posteriormente, as amostras de solo foram transferidas para os vasos, no dia 10/09/2014. A seguir, adicionou-se água em cada vaso, equivalente a $80 \%$ da água disponível total (ADT) por um período de incubação de 20 dias. Para os tratamentos que consistiram na aplicação de calcário líquido, o produto comercial foi aplicado dois dias antes da semeadura do feijão (dia 28/09/2014), sem incorporação prévia.

Por ocasião da semeadura, foram aplicados $10 \mathrm{mg} \mathrm{dm}^{-3} \mathrm{de} \mathrm{N}$ (ureia), $60 \mathrm{mg} \mathrm{dm}^{-3} \mathrm{P}_{2} \mathrm{O}_{5}$ (superfosfato triplo) e $30 \mathrm{mg} \mathrm{dm}^{-3} \mathrm{de}_{2} \mathrm{O}$ (cloreto de potássio) para todos os tratamentos e incorporado ao solo a $5 \mathrm{~cm}$ de profundidade, ao lado e abaixo das sementes cerca de $3 \mathrm{~cm}$. A semeadura foi realizada em 30/09/2014, utilizando-se três sementes por vaso e a emergência das plântulas ocorreu 5 dias após o plantio, dia 05/10/2014. As sementes foram tratadas com o fungicida Thiram (150 mL $100 \mathrm{~kg}^{-1}$ sementes $)$, para o controle preventivo da 
antracnose (Colletotrichum lindemuthianum) e podridão-radicular (Rhizoctonia solani). Uma semana após a emergência, foi realizado desbaste, para deixar uma planta por vaso. Aos 9 e 23 dias após emergência (DAE), foram efetuadas duas adubações nitrogenadas de cobertura, aplicando-se $70 \mathrm{mg} \mathrm{dm}^{-3}$ de $\mathrm{N}$ (ureia) em cada vaso, por adubação.

A necessidade de irrigação foi detectada mediante pesagem diária de quatro vasos para cada dose de calcário, colocando-se água em quantidade suficiente para elevar a umidade a $100 \%$ da ADT sempre que o nível atingia $80 \%$ da ADT. Foram coletadas amostras do solo de cada tratamento para análise química dos teores de P, M.O., $\mathrm{K}, \mathrm{Ca}, \mathrm{Mg}$, S, B, Cu, Fe, Mn e Zn, pH, H + Al, SB, CTC e V\% (RAIJ et al., 2001), aos 42 dias após o plantio (DAP), equivalente à e 47 dias após a emergência (DAE) do feijoeiro, quanto a cultura se encontrava em florescimento pleno. Aos $48 \mathrm{DAE}$, as plantas foram ceifadas e separadas em parte aérea e raízes. O material vegetal separado foi acondicionado em estufa de circulação de ar a $60^{\circ} \mathrm{C}$ por $72 \mathrm{~h}$, posteriormente este material vegetal foi moído e foram realizadas as análises químicas foliares de parte aérea e raiz para determinação dos teores de $\mathrm{N}, \mathrm{P}, \mathrm{K}, \mathrm{Ca}, \mathrm{Mg}, \mathrm{S}, \mathrm{Cu}, \mathrm{Fe}, \mathrm{Mn}$ e Zn, de acordo com metodologia proposta por Malavolta et al. (1997).

Os resultados foram analisados pela análise de variância (teste $\mathrm{F}$ ) e comparados pelo teste de Tukey a 5\% de probabilidade para comparação de médias das fontes de calcário e, ajustadas a equações de regressão para o efeito das doses de calcário, utilizando-se o programa SISVAR (FERREIRA, 2011).

\section{RESULTADOS E DISCUSSÃO}

$\mathrm{O}$ aumento das doses, assim como as fontes de calcário não propiciaram efeito sobre os teores de matéria orgânica e P do solo (Tabela 1). As doses de calcário influenciaram o teor de $\mathrm{K}$ no solo, com ajuste à função quadrática com menor teor dessa base trocável sendo alcançado na dose de $135 \%$ da dose de referência, o que pode ser explicado pela maior absorção de K pelo feijoeiro. Houve interação significativa entre doses e fontes de calcário para os teores de $\mathrm{Ca}$ e $\mathrm{Mg}$ do solo. A fonte de calcário em pó proporcionou teores de $\mathrm{Ca} \mathrm{e}$ $\mathrm{Mg}$ superiores a fonte de calcário líquida na meia dose, na dose cheia e na dose dupla (Tabela 2). Houve ajuste a função quadrática para doses de calcário em pó, com o ponto de máxima dose para os teores de $\mathrm{Ca}$ e $\mathrm{Mg}$ sendo obtidos com 95 e $91 \%$ da dose de referência, respectivamente. Para as doses do calcário líquido não houve influência, sendo indicativo de que esta fonte forneceu muito pouco $\mathrm{Ca}$ e $\mathrm{Mg}$ ao sistema radicular da cultura, sendo menos eficiente comparativamente ao calcário dolomítico em pó como fonte dessas base trocáveis.

Resultados semelhantes foram obtidos por Mattiello et al. (2006), que verificaram aumento do teor de $\mathrm{Ca}$ no solo e diminuição do teor de $\mathrm{Al}$ em função do incremento das doses de calcário dolomítico, trabalhando com doses para elevar a V\% à 30, 45, 60,75, 80 e 95\%. Para o teor de Mg, Mattiello et al. (2006) não encontraram diferenças entre o solo

Cultura Agronômica, Ilha Solteira, v.26, n.3, p.265-284, 2017 
natural e entre as doses de calcário aplicadas. Diferindo assim, do observado neste estudo, onde os teores de $\mathrm{Mg}$ aumentaram em função do aumento das doses de corretivo em pó.

Tabela 1. Teores médios de P, M.O., K, Ca e Mg do solo em função de doses e fontes de calcário. Ilha Solteira - SP, Brasil, 2014.

\begin{tabular}{cccccc}
\hline Doses $^{\#}$ & $\begin{array}{c}\mathrm{P} \\
\left(\mathrm{mg} \mathrm{dm}^{-3}\right)\end{array}$ & $\begin{array}{c}\text { M.O. } \\
\left(\mathrm{g} \mathrm{dm}^{-3}\right)\end{array}$ & $\begin{array}{c}\mathrm{K} \\
\left(\mathrm{mmol}_{\mathrm{c}} \mathrm{dm}^{-3}\right)\end{array}$ & $\begin{array}{c}\mathrm{Ca} \\
\left(\mathrm{mmol}_{\mathrm{c}} \mathrm{dm}^{-3}\right)\end{array}$ & $\begin{array}{c}\mathrm{Mg} \\
\left(\mathrm{mmol}_{\mathrm{c}} \mathrm{dm}^{-3}\right)\end{array}$ \\
\hline 0 & 66,00 & 29,50 & $5,00^{(1)}$ & 43,00 & 26,00 \\
0,5 & 65,75 & 29,00 & 4,68 & 54,00 & 36,00 \\
1 & 56,50 & 29,25 & 4,28 & 45,75 & 30,00 \\
2 & 60,50 & 29,75 & 4,48 & 46,25 & 29,75 \\
\hline Fontes & & & & \\
\hline Pó & $63,88 \mathrm{a}$ & $29,50 \mathrm{a}$ & $4,68 \mathrm{a}$ & 52,88 & 36,00 \\
Líquido & $60,50 \mathrm{a}$ & $29,25 \mathrm{a}$ & $4,54 \mathrm{a}$ & 41,63 & 24,88 \\
\hline D.M.S. (5\%) & 16,95 & 1,61 & 0,31 & 2,78 & 3,25 \\
Média Geral & 62,19 & 29,38 & 4,61 & 47,25 & 30,44 \\
C.V. (\%) & 23,05 & 4,64 & 5,74 & 4,98 & 9,03 \\
\hline
\end{tabular}

\# Doses 0; 0,5; 1 e 2 referem-se as doses aplicadas nos tratamentos, proporcionalmente, onde para o calcário em pó a dose 1 equivale à $2,5 \mathrm{t} \mathrm{ha}^{-1}$, e para o calcário líquido a dose 1 equivale à $5 \mathrm{~L}$ por tonelada de calcário em pó a ser aplicada.

Médias seguidas de mesma letra na coluna não diferem pelo teste de Tukey a $5 \%$ de probabilidade.

(1) $y=5,0334-1,0984 x+0,4068 x^{2}\left(R^{2}=0,95 *\right)$

Tabela 2. Interação entre fontes e doses de calcário nos teores de $\mathrm{Ca}$ e $\mathrm{Mg}$ do solo. Ilha Solteira - SP, Brasil, 2014.

\begin{tabular}{|c|c|c|c|c|}
\hline \multirow[t]{2}{*}{ Fontes } & \multicolumn{4}{|c|}{ Doses $^{\#}$} \\
\hline & 0 & 0,5 & 1 & 2 \\
\hline & \multicolumn{4}{|c|}{ Teor de Ca no solo $\left(\mathrm{mmol}_{\mathrm{c}} \mathrm{dm}^{-3}\right)$} \\
\hline$P^{(1)}$ & $43,00 \mathrm{a}$ & $68,00 \mathrm{a}$ & $49,00 \mathrm{a}$ & $51,50 \mathrm{a}$ \\
\hline Líquido & $43,00 \mathrm{a}$ & $40,00 \mathrm{~b}$ & $42,50 \mathrm{~b}$ & $41,00 \mathrm{~b}$ \\
\hline \multirow[t]{2}{*}{ D.M.S. } & \multicolumn{4}{|c|}{5,56} \\
\hline & \multicolumn{4}{|c|}{ Teor de $\mathrm{Mg}$ no solo $\left(\mathrm{mmol}_{\mathrm{c}} \mathrm{dm}^{-3}\right)$} \\
\hline Pó $^{(2)}$ & $26,00 \mathrm{a}$ & $48,00 \mathrm{a}$ & $35,00 \mathrm{a}$ & $35,00 \mathrm{a}$ \\
\hline Líquido & $26,00 \mathrm{a}$ & $24,00 \mathrm{~b}$ & $25,00 \mathrm{~b}$ & $24,50 \mathrm{~b}$ \\
\hline
\end{tabular}

\footnotetext{
\# Doses 0; 0,5; 1 e 2 referem-se as doses aplicadas nos tratamentos, proporcionalmente, onde para o calcário em pó a dose 1 equivale à $2,5 \mathrm{t} \mathrm{ha}^{-1}$, e para o calcário líquido a dose 1 equivale à $5 \mathrm{~L}$ por tonelada de calcário em pó a ser aplicada.

Médias seguidas de mesma letra na coluna não diferem pelo teste de Tukey a 5\% de probabilidade.

(1) $\mathrm{y}=47,7046+20,2955 \mathrm{x}-9,5909 \mathrm{x}^{2}\left(\mathrm{R}^{2}=0,21 *\right.$ e $\left.\mathrm{PM}=0,95\right)$

(2) $\mathrm{y}=29,5727+23,0273 \mathrm{x}-10,4545 \mathrm{x}^{2}\left(\mathrm{R}^{2 *}=0,37 * *\right.$ e $\left.\mathrm{PM}=0,91\right)$
}

Cultura Agronômica, Ilha Solteira, v.26, n.3, p.265-284, 2017 
Diferentemente, Barbosa Filho et al. (2005), estudando doses de calcário (zero, 1/3 e $2 / 3$ da necessidade de calagem calculada para elevar a saturação por bases para 60\%) observaram que entre os atributos de fertilidade, apenas o $\mathrm{pH}$ foi influenciado significativamente pela calagem, o que segundo os autores foi influenciado pelo fator quantidade (dose), que não foi suficiente para alterar significativamente os teores de Ca e Mg trocáveis, a acidez potencial e a porcentagem de saturação por bases, pois o tempo de 24 meses de reação do calcário com o solo é considerado suficiente para liberar $\mathrm{Ca}$ e $\mathrm{Mg}$ e elevar a saturação por bases (MELLO et al., 2003), visto que, segundo Caires et al. (2000) e Mello et al. (2003), a ação da calagem está relacionada com a quantidade e o tempo de reação com o solo, mesmo quando ocorre a incorporação do calcário, como no presente trabalho, o qual foi realizado com intuito de se avaliar o efeito da calagem a curto prazo.

Tabela 3. Teores médios de SB, S, CTC, V e acidez potencial (H+Al) do solo em função de doses e fontes de calcário. Ilha Solteira-SP, Brasil, 2014

\begin{tabular}{ccccccc}
\hline Doses $^{\#}$ & $\begin{array}{c}\mathrm{SB} \\
\left(\mathrm{mmol}_{\mathrm{c}} \mathrm{dm}^{-3}\right)\end{array}$ & $\begin{array}{c}\mathrm{S} \\
\left(\mathrm{mg} \mathrm{dm}^{-3}\right)\end{array}$ & $\begin{array}{c}\mathrm{CTC} \\
\left(\mathrm{mmol}_{\mathrm{c}} \mathrm{dm}^{-3}\right)\end{array}$ & $\begin{array}{c}\mathrm{V} \\
(\%)\end{array}$ & $\begin{array}{c}\mathrm{pH} \\
\left(\mathrm{CaCl}_{2}\right)\end{array}$ & $\begin{array}{c}\mathrm{H}+\mathrm{Al} \\
\left(\mathrm{mmol}_{\mathrm{c}} \mathrm{dm}^{-3}\right)\end{array}$ \\
\hline 0 & 74,00 & 13,50 & 106,00 & 70,00 & 5,66 & 28,93 \\
0,5 & 94,68 & 19,75 & 120,43 & 77,25 & 6,01 & 24,46 \\
1 & 80,03 & 16,25 & 109,03 & 73,25 & 5,93 & 25,32 \\
2 & 80,48 & 13,50 & 110,23 & 72,75 & 5,79 & 27,64 \\
\hline Fontes & & & & & \\
\hline Pó & 93,55 & $18,00 \mathrm{a}$ & 119,43 & 77,75 & 6,02 & 23,98 \\
Líquido & 71,04 & $13,50 \mathrm{a}$ & 103,41 & 68,88 & 5,67 & 29,20 \\
\hline D.M.S. (5\%) & 5,50 & 6,89 & 4,29 & 2,72 & 0,05 & 0,78 \\
Média Geral & 82,29 & 15,75 & 111,42 & 73,31 & 5,84 & 26,59 \\
C.V. (\%) & 5,65 & $16,04^{\# \#}$ & 3,26 & 3,13 & 2,03 & 7,78 \\
\hline
\end{tabular}

\# Doses 0; 0,5; 1 e 2 referem-se as doses aplicadas nos tratamentos, proporcionalmente, onde para o calcário em pó a dose 1 equivale à $2,5 \mathrm{t} \mathrm{ha}^{-1}$, e para o calcário líquido a dose 1 equivale à $5 \mathrm{~L}$ por tonelada de calcário em pó a ser aplicada.

Médias seguidas de mesma letra na coluna não diferem pelo teste de Tukey a 5\% de probabilidade.

\#\# Dados corrigidos seguindo a equação $(\mathrm{x}+0,5)^{0,5}$. Médias reais apresentadas.

Com relação à $\mathrm{SB}$, teor de $\mathrm{S}, \mathrm{CTC}, \mathrm{V} \%, \mathrm{pH}$ e $\mathrm{H}+\mathrm{Al}$ no solo (Tabela 3), o incremento das doses de calcário não influenciou isoladamente estes atributos químicos. Contudo, verificou-se que conforme observado para os teores de $\mathrm{Ca}$ e $\mathrm{Mg}$, numericamente, metade da dose de referência propiciou maior $\mathrm{SB}$, teor de $\mathrm{S}, \mathrm{CTC}$, V\% e $\mathrm{pH}$ e menor $\mathrm{H}+\mathrm{Al}$. Enquanto que, a interação entre doses e fontes de calcário foi significativa na $\mathrm{SB}, \mathrm{CTC}, \mathrm{V} \%, \mathrm{pH}$ e $\mathrm{H}+\mathrm{Al}$. A fonte de calcário em pó apresentou SB, CTC, V\% e $\mathrm{pH}$ superiores a fonte de calcário líquida na meia dose, na dose cheia e na dose dupla. Houve ajuste a função quadrática para SB, CTC e V\% apenas nas doses de calcário em pó, com ponto de máxima dose em 93, 94, 90 e 110\% da dose de referência, respectivamente (Tabela 4). A fonte de calcário líquido foi superior a fonte de calcário em pó na meia dose, na dose cheia e na dose 
dupla para a $\mathrm{H}+\mathrm{Al}$, demonstrando sua ineficiência na correção da acidez. Não houve ajuste para o calcário líquido sobre tal avaliação, porém verificou-se ajuste a função quadrática para doses de calcário em pó (Tabela 4$)$, sendo a dose ótima estimada $\left(2,7 \mathrm{t} \mathrm{ha}^{-1}\right)$ próxima da dose recomendada $\left(2,5 \mathrm{t} \mathrm{ha}^{-1}\right)$ para obtenção da menor acidez potencial do solo com feijoeiro.

Tabela 4. Interação entre fontes e doses de calcário relacionados à soma de bases (SB), CTC, V\% e H+Al do solo. Ilha Solteira - SP, Brasil, 2014.

\begin{tabular}{|c|c|c|c|c|}
\hline \multirow[t]{2}{*}{ Fontes } & \multicolumn{4}{|c|}{ Doses $^{\#}$} \\
\hline & 0 & 0,5 & 1 & 2 \\
\hline & \multicolumn{4}{|c|}{$\mathrm{SB}\left(\mathrm{mmol}_{\mathrm{c}} \mathrm{dm}^{-3}\right)$} \\
\hline$P^{\prime}{ }^{(1)}$ & $74,00 \mathrm{a}$ & $120,95 \mathrm{a}$ & $88,25 \mathrm{a}$ & $91,00 \mathrm{a}$ \\
\hline Líquido & $74,00 \mathrm{a}$ & $68,40 \mathrm{~b}$ & $71,80 \mathrm{~b}$ & $69,95 \mathrm{~b}$ \\
\hline \multirow[t]{2}{*}{ D.M.S. } & \multicolumn{4}{|c|}{11,00} \\
\hline & \multicolumn{4}{|c|}{ CTC $\left(\mathrm{mmol}_{\mathrm{c}} \mathrm{dm}^{-3}\right)$} \\
\hline $\mathrm{Pó}^{(2)}$ & $106,00 \mathrm{a}$ & $139,95 \mathrm{a}$ & $113,75 \mathrm{a}$ & $118,00 \mathrm{a}$ \\
\hline Líquido & $106,00 \mathrm{a}$ & $100,90 \mathrm{~b}$ & $104,30 \mathrm{~b}$ & $102,45 \mathrm{~b}$ \\
\hline \multirow[t]{2}{*}{ D.M.S. } & \multicolumn{4}{|c|}{8,58} \\
\hline & \multicolumn{4}{|c|}{$\mathrm{V}(\%)$} \\
\hline $\mathrm{Pó}^{(3)}$ & $70,00 \mathrm{a}$ & $86,50 \mathrm{a}$ & $77,50 \mathrm{a}$ & $77,00 \mathrm{a}$ \\
\hline Líquido & $70,00 \mathrm{a}$ & $68,00 \mathrm{~b}$ & $69,00 \mathrm{~b}$ & $68,50 \mathrm{~b}$ \\
\hline \multirow[t]{2}{*}{ D.M.S. } & \multicolumn{4}{|c|}{5,43} \\
\hline & \multicolumn{4}{|c|}{$\mathrm{pH}$} \\
\hline $\mathrm{Pó}^{(4)}$ & $5,66 \mathrm{a}$ & $6,34 \mathrm{a}$ & $6,14 \mathrm{a}$ & $5,95 \mathrm{a}$ \\
\hline Líquido & $5,66 \mathrm{a}$ & $5,68 \mathrm{~b}$ & $5,71 \mathrm{~b}$ & $5,62 \mathrm{~b}$ \\
\hline \multirow[t]{2}{*}{ D.M.S. } & \multicolumn{4}{|c|}{0,09} \\
\hline & \multicolumn{4}{|c|}{$\mathrm{H}+\mathrm{Al}\left(\mathrm{mmol}_{\mathrm{c}} \mathrm{dm}^{-3}\right)$} \\
\hline$P^{\prime(5)}$ & $28,93 \mathrm{a}$ & $19,79 \mathrm{~b}$ & $22,00 \mathrm{~b}$ & $25,21 \mathrm{~b}$ \\
\hline Líquido & $28,93 \mathrm{a}$ & $29,14 \mathrm{a}$ & $28,64 \mathrm{a}$ & $30,07 \mathrm{a}$ \\
\hline
\end{tabular}

\# Doses 0; 0,5; 1 e 2 referem-se as doses aplicadas nos tratamentos, proporcionalmente, onde para o calcário em pó a dose 1 equivale à $2,5 \mathrm{t} \mathrm{ha}^{-1}$, e para o calcário líquido a dose 1 equivale à $5 \mathrm{~L}$ por tonelada de calcário em pó a ser aplicada.

Médias seguidas de mesma letra na coluna não diferem pelo teste de Tukey a 5\% de probabilidade.

(1) $\mathrm{y}=82,37546+42,3345 \mathrm{x}-19,7091 \mathrm{x}^{2}\left(\mathrm{R}^{2}=0,27 * *\right.$ e $\left.P M=0,93\right)$

(2) $\mathrm{y}=112,4664+26,7436 \mathrm{x}-12,5273 \mathrm{x}^{2}\left(\mathrm{R}^{2}=0,20 * *\right.$ e $\left.\mathrm{PM}=0,94\right)$

(3) $\mathrm{y}=72,5636+18,3364 \mathrm{x}-8,2727 \mathrm{x}^{2}\left(\mathrm{R}^{2}=0,41 * *\right.$ e $\left.\mathrm{PM}=0,90\right)$

(4) $\mathrm{y}=5,7364+1,0221 \mathrm{x}-0,4643 \mathrm{x}^{2}\left(\mathrm{R}^{2}=0,70 * *\right.$ e $\left.\mathrm{PM}=1,1\right)$

(5) $y=27,9662-14,5662 x+6,6753 x^{2}\left(R^{2}=0,76^{* *}\right)$

Cultura Agronômica, Ilha Solteira, v.26, n.3, p.265-284, 2017 
A maior disponibilização de Ca e Mg do calcário dolomítico influenciou na SB, com reflexo na CTC e V\%, elucidando ainda a questão de que o calcário líquido não conseguiu disponibilizar $\mathrm{Ca}$ e $\mathrm{Mg}$ e diminuir a acidez potencial do solo de maneira semelhante ao calcário em pó, não sendo eficiente na correção de acidez do solo, como constatado em função da diferença nos valores de $\mathrm{H}+\mathrm{Al}$ entre as fontes. $\mathrm{O}$ fato de ser recomendada e aplicada uma quantidade muito pequena do calcário líquido sem incorporação ao solo pode explicar estes resultados insatisfatórios, diferentemente dos resultados obtidos por Nascente e Cobucci (2015), que trabalhando com doses de calcário líquido (0, 1.050, 2.100, 4.200, 8.400 e $12.600 \mathrm{~g} \mathrm{ha}^{-1}$ de $\mathrm{CaCO}_{3}$ ) na cultura do feijoeiro verificaram que a aplicação de pequena quantidade de solução com calcário na forma de micropartículas elevou o $\mathrm{pH}$ do solo e reduziu a saturação de Al no sulco de semeadura, com reflexo positivo na produtividade de grãos da cultura. Contudo, salienta-se que, quando comparado com o solo sem aplicação de calcário (testemunha) (Tabela 1), houve pequena redução da $\mathrm{H}+\mathrm{Al}$ e aumento dos teores de $\mathrm{Ca}$ com a aplicação de calcário líquido.

Vale ressaltar que a diferença de magnitude de resposta à calagem se deve principalmente à acidez potencial e pH de cada solo. A tendência é de que um solo mais ácido apresente maior resposta à correção comparativamente a um solo menos ácido, embora mesmo em condições de pH no solo favoráveis (6,0 a 6,5 em água) seja possível observar o efeito corretivo da calagem, apesar disto não ter sido constatado no presente estudo, possivelmente em função da adaptabilidade do cultivar quanto a fertilidade inicial do solo.

Tais resultados elucidam a questão de que o manejo adequado dos solos é baseado na manutenção do pH, evitando aplicação de elevadas doses de calcário. De acordo com Rossielo e Jacob Netto (2006), as plantas dicotiledôneas, como o feijoeiro, possuem em suas superfícies celulares alta densidade de cargas, as quais favorecem os íons trivalentes, como o Al, a estabelecerem uma interação muito forte com estas superfícies, de maneira tal que praticamente entram em "colapso", formando ligações quase covalentes e, neste caso, dificilmente são substituídos nas superfícies de troca, reduzindo a capacidade de troca de cátions das raízes das plantas. A permanência do $\mathrm{Al}^{+3}$ nesses sítios interfere no alongamento das raízes, na absorção de nutrientes, principalmente, o cálcio, que é um elemento indispensável para o funcionamento das membranas celulares, reduzindo, desta forma, o desenvolvimento da cultura. Quando o $\mathrm{pH}$ em $\mathrm{CaCl}_{2}$ do solo está acima de 5,5, todo o alumínio tóxico já foi precipitado, não afetando sobremaneira, o desenvolvimento radicular e consequentemente o crescimento e produtividade da cultura. Mesmo na testemunha, o $\mathrm{pH}$ em $\mathrm{CaCl}_{2}$ obtido após 20 dias de aplicação dos tratamentos apresentava-se maior que o preconizado como limitante ao desenvolvimento radicular pela presença de Al tóxico, justificando porque o Al tóxico não foi fator limitante no desenvolvimento da cultura do feijoeiro no presente trabalho.

No que se refere ao $\mathrm{pH}$, resultado semelhante verificado por Sousa et al. (2013), trabalhando com doses de calcário dolomítico $\left(0,1,2,3,4,5,8\right.$ e 10 t ha $\left.\mathrm{ha}^{-1}\right)$ em Argissolo 
Vermelho-Amarelo distrófico, que constataram aumento do $\mathrm{pH}$ após 30 dias de aplicação dos tratamentos de 5,15 na testemunha para 7,26 na maior dose (10 t ha $\left.{ }^{-1}\right)$, corroborando com o resultado observado por Silva et al. (2008) e Nicolodi et al. (2008) para amostras de Organossolos e Latossolo Vermelho distrófico respectivamente. Silva et al. (2004), trabalhando com doses de calcário dolomítico $\left(0 ; 1,59 ; 3,18\right.$ e 4,48 $\left.\mathrm{t} \mathrm{ha}^{-1}\right)$ e cultivares de feijoeiro (Campeão 1, Carioca, FT-Bonito e Pérola), verificaram que o aumento das doses de calcário proporcionou elevação do $\mathrm{pH}, \mathrm{Ca}$ e $\mathrm{Mg}$ trocáveis e redução nos teores de $\mathrm{Al}$ trocável e H+Al, evidenciando o efeito positivo dessa prática.

Na literatura, o pH do solo ideal, para a absorção da maioria dos nutrientes para a cultura do feijão, situa-se próximo de 6,0, como verificado neste trabalho. A diminuição dos valores de $\mathrm{H}+\mathrm{Al}$ e ausência de $\mathrm{Al}$ tóxico para as plantas, assim como aumento dos teores de $\mathrm{Ca}$ e valores estatisticamente iguais de $\mathrm{P}$, quando comparado com o solo sem aplicação de calcário, indicam que para os tratamentos aplicados não houve precipitação de $\mathrm{P}$.

Tabela 5. Teores médios de $\mathrm{B}, \mathrm{Cu}, \mathrm{Fe}, \mathrm{Mn}$ e $\mathrm{Zn}$ do solo em função de doses e fontes de calcário. Ilha Solteira-SP, Brasil, 2014.

\begin{tabular}{ccrccc}
\hline Doses $^{\#}$ & $\mathrm{~B}$ & $\mathrm{Cu}$ & $\mathrm{Fe}$ & $\mathrm{Mn}$ & $\mathrm{Zn}$ \\
\cline { 2 - 5 } & --------------------- & $\left(\mathrm{mg} \mathrm{dm}^{-3}\right)$ \\
\hline 0 & 0,18 & 10,75 & 39,00 & 144,60 & 3,10 \\
0,5 & 0,37 & 9,73 & 33,00 & 118,75 & 5,98 \\
1 & 0,25 & 10,73 & 38,25 & 141,60 & 3,93 \\
2 & 0,18 & 10,95 & 34,50 & 139,23 & 3,00 \\
\hline Fontes & & & & & \\
\hline Pó & $0,22 \mathrm{a}$ & 10,20 & 33,00 & 122,08 & $4,18 \mathrm{a}$ \\
Líquido & $0,27 \mathrm{a}$ & 10,88 & 39,38 & 150,01 & $3,83 \mathrm{a}$ \\
\hline D.M.S. (5\%) & 0,18 & 0,59 & 5,53 & 10,14 & 2,15 \\
Média Geral & 0,24 & 10,54 & 36,19 & 136,04 & 4,00 \\
C.V. (\%) & $9,84^{\# \#}$ & 4,74 & 12,92 & 6,30 & $18,16^{\# \#}$ \\
\hline
\end{tabular}

\# Doses 0; 0,5; 1 e 2 referem-se as doses aplicadas nos tratamentos, proporcionalmente, onde para o calcário em pó a dose 1 equivale à $2,5 \mathrm{t} \mathrm{ha}^{-1}$, e para o calcário líquido a dose 1 equivale à $5 \mathrm{~L}$ por tonelada de calcário em pó a ser aplicada.

${ }^{\#}$ Dados corrigidos seguindo a equação $(x+0,5)^{0,5}$. Médias reais apresentadas.

Médias seguidas de mesma letra na coluna não diferem pelo teste de Tukey a $5 \%$ de probabilidade.

Os teores de S (Tabela 3) e de B, Cu, Fe Mn e Zn não foram influenciados pelas doses de calcário aplicadas (Tabela 5), porém ressalta-se que em relação à testemunha, em média, houve incrementos de 16,7; 33,3 e 29,0\% para os teores de S, B e Zn, respectivamente, o que pode ser explicado pela aceleração da mineralização destes nutrientes contidos na matéria orgânica do solo. Por outro lado, os teores de P, Cu, Fe e Mn foram 5,8; 2,0; 7,2 e $6,0 \%$ inferiores, em média, nos tratamentos que receberam a aplicação de calcário (Tabelas 1, 3 e 5), provavelmente devido, a elevação do $\mathrm{pH}$ constatada nos tratamentos que 
receberam calcário dolomítico e reduziram um pouco a disponibilidade destes nutrientes. Schultz et al. (2011) observaram redução nos teores de P e K do solo em função das doses de calcário aplicadas, o que segundo os autores pode estar associada à maior extração destes nutrientes pela cultura que estaria sendo favorecida pela correção do solo. Estes resultados são corroborados por Mattiello et al. (2006), que verificaram redução dos teores de P e K de acordo com o aumento da saturação por bases e atribuíram este padrão a maior absorção destes nutrientes pela cultura.

Tabela 6. Interação entre fontes e doses de calcário nos teores de $\mathrm{Cu}, \mathrm{Fe}$ e $\mathrm{Mn}$ do solo. Ilha Solteira - SP, Brasil, 2014.

\begin{tabular}{|c|c|c|c|c|}
\hline \multirow[t]{2}{*}{ Fontes } & \multicolumn{4}{|c|}{ Doses $^{\#}$} \\
\hline & 0 & 0,5 & 1 & 2 \\
\hline & \multicolumn{4}{|c|}{ Teor de $\mathrm{Cu}$ no solo $\left(\mathrm{mg} \mathrm{dm}^{-3}\right)$} \\
\hline $\mathrm{Pó}^{(1)}$ & $10,75 \mathrm{a}$ & $9,15 \mathrm{a}$ & $10,05 \mathrm{~b}$ & $10,85 \mathrm{a}$ \\
\hline Líquido & $10,75 \mathrm{a}$ & $10,30 \mathrm{a}$ & $11,40 \mathrm{a}$ & $11,05 \mathrm{a}$ \\
\hline \multirow[t]{2}{*}{ D.M.S. } & \multicolumn{4}{|c|}{1,18} \\
\hline & \multicolumn{4}{|c|}{ Teor de Fe no solo $\left(\mathrm{mg} \mathrm{dm}^{-3}\right)$} \\
\hline \multirow[t]{2}{*}{ Fontes } & \multicolumn{4}{|c|}{ Doses $^{\#}$} \\
\hline & 0 & 0,5 & 1 & 2 \\
\hline Pó & $39,00 \mathrm{a}$ & $25,50 \mathrm{~b}$ & $33,50 \mathrm{a}$ & $34,00 \mathrm{a}$ \\
\hline Líquido & $39,00 \mathrm{a}$ & $40,50 \mathrm{a}$ & $43,00 \mathrm{a}$ & $35,00 \mathrm{a}$ \\
\hline \multirow[t]{2}{*}{ D.M.S. } & \multicolumn{4}{|c|}{11,05} \\
\hline & \multicolumn{4}{|c|}{ Teor de $\mathrm{Mn}$ no solo $\left(\mathrm{mg} \mathrm{dm}^{-3}\right)$} \\
\hline \multirow[t]{2}{*}{ Fontes } & \multicolumn{4}{|c|}{ Doses $^{\#}$} \\
\hline & 0 & 0,5 & 1 & 2 \\
\hline $\mathrm{Pó}^{(2)}$ & $144,60 \mathrm{a}$ & $95,15 \mathrm{~b}$ & $117,40 \mathrm{~b}$ & $131,15 \mathrm{a}$ \\
\hline Líquido & $144,60 \mathrm{a}$ & $142,35 \mathrm{a}$ & $165,80 \mathrm{a}$ & $147,30 \mathrm{a}$ \\
\hline D.M.S. & \multicolumn{4}{|c|}{20,28} \\
\hline \multicolumn{5}{|c|}{$\begin{array}{l}\text { \# Doses } 0 ; 0,5 ; 1 \text { e } 2 \text { referem-se as doses aplicadas nos tratamentos, proporcionalmente, onde para } \mathrm{o} \\
\text { em pó a dose } 1 \text { equivale à } 2,5 \mathrm{t}^{-1} \text {, e para o calcário líquido a dose } 1 \text { equivale à } 5 \mathrm{~L} \text { por tonelada de } \\
\text { em pó a ser aplicada. } \\
\text { Médias seguidas de mesma letra na coluna não diferem pelo teste de Tukey a } 5 \% \text { de probabilidade. } \\
\text { (1) } \mathrm{y}=10,5182-2,0682 \mathrm{x}+1,1364 \mathrm{x}^{2}\left(\mathrm{R}^{2}=0,65^{*}\right) \\
\text { (2) } \mathrm{y}=137,8950-65,5550 \mathrm{x}+31,6500 \mathrm{x}^{2}\left(\mathrm{R}^{2}=0,59^{* *}\right)\end{array}$} \\
\hline
\end{tabular}

Para os teores de $\mathrm{Cu}$ no solo, o calcário líquido foi superior estatisticamente à fonte de calcário em pó na dose cheia, este resultado se repetiu numericamente na metade e no dobro da dose de referência. Houve ajuste a função quadrática para doses na fonte de calcário em pó, sendo o menor teor de $\mathrm{Cu}$ obtido com aplicação de $91 \%$ da dose de referência (Tabela $6)$. 
No desdobramento da interação doses e fontes nos teores de Fe, o calcário líquido foi superior ao calcário em pó na meia dose, numericamente a fonte líquida também foi superior à fonte em pó na dose de referência e na dose dupla (Tabela 6).

A interação foi significativa entre doses e fontes sobre os teores de Mn do solo, onde o calcário líquido foi superior ao calcário em pó na meia dose e na dose cheia, embora numericamente a fonte líquida tenha sido superior à fonte em pó na dose dupla. Houve ajuste a função quadrática para doses na fonte de calcário em pó, com o menor teor de $\mathrm{Fe}$ obtido com aplicação de $103 \%$ da dose de referência (Tabela 6).

A maior disponibilidade dos micronutrientes catiônicas ocorre quando o $\mathrm{pH}$ apresenta valores mais baixos, ou seja, a acidificação do solo favorece a disponibilização destes nutrientes. $\mathrm{O}$ que se verifica com os resultados obtidos é que a tendência de maiores teores de $\mathrm{Cu}, \mathrm{Fe}$ e $\mathrm{Mn}$ ocorrerem quando a fonte utilizada foi o calcário líquido, o que confirma que esta fonte não conseguiu elevar o pH do solo e corrigir a acidez como o observado para o calcário dolomítico em pó.

Os resultados obtidos neste trabalho se assemelham aos encontrados por Schultz et al. (2011), em decorrência do aumento das doses de calcário (doses calculadas em função dos níveis de saturação por bases do solo (V\%): 30; 45; 60; 75 e 100\% e o controle, com saturação natural do solo) em um Organossolo cultivado com feijoeiro, constataram que ocorreu elevação da saturação por bases e aumentos nos valores de $\mathrm{pH}(4,53$ a 7,12), aumento dos teores de Ca (22,6 a 137,0 mmol $\left.\mathrm{dm}^{-3}\right)$ e $\mathrm{Mg}\left(12,4\right.$ a 101,6 $\left.\mathrm{mmol}_{\mathrm{c}} \mathrm{dm}^{-3}\right)$, paralelos à redução da acidez potencial (18,5 a 25,9 $\left.\mathrm{mmol}_{\mathrm{c}} \mathrm{dm}^{-3}\right)$, corroborando com os resultados obtidos por Cardozo et al. (2008), que observaram maior $\mathrm{H}+\mathrm{Al}\left(219,5 \mathrm{mmol}_{\mathrm{c}} \mathrm{dm}^{-}\right.$ ${ }^{3}$ ) e menores teores de $\mathrm{Ca}+\mathrm{Mg}\left(64,8 \mathrm{mmol}_{\mathrm{c}} \mathrm{dm}^{-3}\right)$ e $\mathrm{pH}(5,27)$ no solo sem aplicação de calcário, em relação ao que recebeu a calagem. Neste último, a $\mathrm{H}+\mathrm{Al}$, os teores de $\mathrm{Ca}$ e $\mathrm{Mg}$ e o valor do $\mathrm{pH}$ foram de 63,0 $\mathrm{mmol}_{\mathrm{c}} \mathrm{dm}^{-3}, 89,6 \mathrm{mmol}_{\mathrm{c}} \mathrm{dm}^{-3}$ e 5,99, respectivamente. Os autores relataram que as diferenças observadas entre as áreas estudadas são decorrentes da calagem realizada. Entretanto, após dois cultivos de milho e trigo em sistema plantio direto, Galindo et al. (2017) verificaram que mesmos aplicando doses altas de N (150 e $200 \mathrm{~kg} \mathrm{ha}$ ${ }^{1}$ ), não houve acidificação do solo e redução dos teores de M.O. e dos mesmos nutrientes estudados.

Os teores médios de $\mathrm{P}, \mathrm{K}, \mathrm{Ca}, \mathrm{Mg}, \mathrm{S}, \mathrm{Cu}, \mathrm{Fe}, \mathrm{Mn}$ e $\mathrm{Zn}$ no solo estavam altos, de acordo com os valores preconizados por Raij et al. (1997), cuja as faixas caracterizadas como alta para estes nutrientes são respectivamente de 41-60 $\mathrm{mg} \mathrm{dm}^{-3} ; 3,1-6,0 ;>7,0,>8$ $\mathrm{mmol}_{\mathrm{c}} \mathrm{dm}^{-3} ;>10 ;>0,8 ;>12 ;>5,0$ e $>1,2 \mathrm{mg} \mathrm{dm}^{-3}$ (Tabelas 1,3 e 5). A V\% variou de média a alta, considerando que a faixa caracterizada como alta é de 71-90\% (Tabela 3). O teor de B no solo ficou dentro do preconizado por Raij et al. (1997) como médio, cuja faixa para tal nutriente é de 0,21-0,60 $\mathrm{mg} \mathrm{dm}^{-3}$ (Tabela 5).

Com relação aos teores de nutrientes (N, P, K, Ca, Mg, S, Cu, Fe, Mn e Zn) na parte aérea do feijoeiro (Tabelas 7 e 8), verificou-se que as doses e fontes de calcário, bem como

Cultura Agronômica, Ilha Solteira, v.26, n.3, p.265-284, 2017 
a interação não influenciaram os teores de nenhum destes nutrientes. Porém, ressalta-se que em relação à testemunha, em média, houve incrementos de 11,70; 33,23 e 44,39\% para os teores de S, Fe e Mn, respectivamente. De acordo com Silva et al. (2007b), a calagem reduziu os teores de $\mathrm{Mn}$ nos cultivares de feijoeiro Campeão1 e Carioca, tanto no sistema radicular, quanto na parte aérea, sendo o inverso observado para a FT-Bonito, que foi a única responsiva ao aumento da calagem. Segundo os autores o aumento do $\mathrm{pH}$ pode ter inibido a absorção do Mn, dada a diminuição na concentração hidrogeniônica, favorecendo, com isso, a conversão do Mn trocável em forma insolúvel, como o $\mathrm{Mn}^{3+}$ e $\mathrm{Mn}^{4+}$ (MALAVOLTA et al., 1997). Segundo Pendias e Pendias (1984), o Ca, Mg e Mn apresentam valência, raio iônico e grau de hidratação semelhantes, ou seja, o aumento da concentração de um inibe a absorção do outro, o que não foi verificado no presente trabalho, com o aumento dos teores de $\mathrm{Ca}$ e $\mathrm{Mg}$ no solo em função das doses de calcário dolomítico.

Tabela 7. Teores médios de $\mathrm{N}, \mathrm{P}, \mathrm{K}, \mathrm{Ca}$ e $\mathrm{Mg}$ da parte aérea do feijoeiro em função de doses e fontes de calcário. Ilha Solteira - SP, Brasil, 2014.

\begin{tabular}{cccccc}
\hline Doses $^{\#}$ & $\mathrm{~N}$ & $\mathrm{P}$ & $\mathrm{K}$ & $\mathrm{Ca}$ & $\mathrm{Mg}$ \\
\hline & 36,85 & 2,65 & 29,00 & 18,85 & 4,85 \\
0,5 & 35,95 & 2,75 & 27,80 & 19,70 & 5,00 \\
1 & 36,58 & 2,75 & 30,18 & 17,83 & 4,95 \\
2 & 34,50 & 2,58 & 29,58 & 16,10 & 4,53 \\
\hline Fontes & & & & & \\
\hline Pó & $35,36 \mathrm{a}$ & $2,65 \mathrm{a}$ & $28,60 \mathrm{a}$ & $18,53 \mathrm{a}$ & $5,06 \mathrm{a}$ \\
Líquido & $36,58 \mathrm{a}$ & $2,71 \mathrm{a}$ & $29,68 \mathrm{a}$ & $17,71 \mathrm{a}$ & $4,60 \mathrm{a}$ \\
\hline D.M.S. (5\%) & 2,83 & 0,25 & 2,45 & 4,48 & 0,74 \\
Média Geral & 35,97 & 2,68 & 29,14 & 18,12 & 4,83 \\
C.V. (\%) & 6,67 & 7,90 & 7,11 & 20,90 & 12,95
\end{tabular}

\# Doses 0; 0,5; 1 e 2 referem-se as doses aplicadas nos tratamentos, proporcionalmente, onde para o calcário em pó a dose 1 equivale à $2,5 \mathrm{t} \mathrm{ha}^{-1}$, e para o calcário líquido a dose 1 equivale à $5 \mathrm{~L}$ por tonelada de calcário em pó a ser aplicada.

Médias seguidas de mesma letra na coluna não diferem pelo teste de Tukey a 5\% de probabilidade.

Por outro lado, o teor de $\mathrm{Cu}$ da parte aérea foi 47,3\% inferior, em média, nos tratamentos que receberam a aplicação de calcário devido a redução da disponibilidade deste micronutriente com a elevação do pH como descrito por Malavolta (1997) e observado na Tabela 7. Silva et al. (2007b) verificaram redução nos teores de $\mathrm{Cu}$ e $\mathrm{Fe}$ tanto na raiz quanto na parte aérea, exceto para a cultivar Campeão 1, que aumentou de forma quadrática o teor de $\mathrm{Cu}$ na raiz até a dose de 2,4 $\mathrm{t} \mathrm{ha}^{-1}$. Segundo os autores, com o aumento do $\mathrm{pH}$, em consequência do incremento das doses de calcário, pode ter ocorrido insolubilização do Fe, diminuindo assim a disponibilidade para as plantas. Outra hipótese seria o efeito diluição, ou seja, a taxa de absorção de $\mathrm{Cu}$ e Fe pelas cultivares não acompanhou proporcionalmente 
a velocidade de acúmulo de matéria seca, o que acarretou menor concentração desses micronutrientes. De acordo com Malavolta (1980), o $\mathrm{Ca}$ e o $\mathrm{Cu}$ apresentam efeito antagônico, ou seja, a presença de um elemento diminui a absorção do outro, cuja toxidez pode ser evitada, uma vez que o $\mathrm{Ca}$ impede a absorção exagerada de $\mathrm{Cu}$, tal premissa não foi verificada no presente trabalho.

Tabela 8. Teores médios de $\mathrm{S}, \mathrm{Cu}, \mathrm{Fe}, \mathrm{Mn}$ e $\mathrm{Zn}$ da parte aérea do feijoeiro em função de doses e fontes de calcário. Ilha Solteira-SP, Brasil, 2014.

\begin{tabular}{|c|c|c|c|c|c|}
\hline Doses $^{\#}$ & $S$ & $\mathrm{Cu}$ & $\mathrm{Fe}$ & $\mathrm{Mn}$ & $\mathrm{Zn}$ \\
\hline & $\left(\mathrm{g} \mathrm{kg}^{-1}\right)$ & --------------- & -----(m & ---------- & -----------. \\
\hline 0 & 2,40 & 37,00 & 1216,5 & 107,0 & 49,00 \\
\hline 0,5 & 2,85 & 18,75 & 1379,5 & 195,0 & 51,25 \\
\hline 1 & 2,73 & 11,50 & 1905,5 & 164,3 & 41,25 \\
\hline 2 & 2,73 & 10,75 & 1981,5 & 151,8 & 55,00 \\
\hline \multicolumn{6}{|l|}{ Fontes } \\
\hline Pó & $2,70 \mathrm{a}$ & $21,00 \mathrm{a}$ & $1555,9 \mathrm{a}$ & $155,6 \mathrm{a}$ & $51,38 \mathrm{a}$ \\
\hline Líquido & $2,65 \mathrm{a}$ & $18,00 \mathrm{a}$ & $1685,6 \mathrm{a}$ & $153,4 \mathrm{a}$ & $46,88 \mathrm{a}$ \\
\hline D.M.S. (5\%) & 0,56 & 19,68 & 992,2 & 56,2 & 8,98 \\
\hline Média Geral & 2,68 & 19,50 & 1620,8 & 154,5 & 49,13 \\
\hline C.V. $(\%)$ & 17,82 & $35,00^{\# \#}$ & $24,77^{\# \#}$ & 30,76 & 15,46 \\
\hline
\end{tabular}

\# Doses 0; 0,5; 1 e 2 referem-se as doses aplicadas nos tratamentos, proporcionalmente, onde para o calcário em pó a dose 1 equivale à $2,5 \mathrm{t} \mathrm{ha}^{-1}$, e para o calcário líquido a dose 1 equivale à $5 \mathrm{~L}$ por tonelada de calcário em pó a ser aplicada.

Médias seguidas de mesma letra na coluna não diferem pelo teste de Tukey a 5\% de probabilidade.

${ }^{\#}$ Dados corrigidos seguindo a equação $(x+0,5)^{0,5}$. Médias reais apresentadas.

$\mathrm{O} \mathrm{K}, \mathrm{Fe}, \mathrm{Mn}$ e $\mathrm{Zn}$ apresentaram teores médios acima do preconizado como adequado por Ambrosano et al. (1997) (Tabela 7 e 8), cuja a faixa adequada para estes nutrientes na folha diagnose (terceiro trifólio com pecíolo) é de 20-24 $\mathrm{g} \mathrm{kg}^{-1}$; 40-140; 15-100 e 0,5-1,5 mg $\mathrm{kg}^{-1}$, respectivamente. Com relação aos teores médios de $\mathrm{N}, \mathrm{P}, \mathrm{Ca}, \mathrm{Mg}, \mathrm{S}$ e $\mathrm{Cu}$ na parte aérea, estes estão dentro do preconizado por Ambrosano et al. (1997) como adequado, cuja faixa de suficiência para tais nutrientes é de, 30-50; 2,5-4,0; 10-25; 2,5-5,0; 2,0-3,0 g kg-1 e 4-20 mg kg-1, respectivamente. Vale ressaltar que a faixa nutricional adequada leva em consideração a análise nutricional da matéria seca foliar, e diferentemente estes resultados apresentados abrangem a parte aérea total, tal fato pode justificar a elevada concentração de $\mathrm{K}$ na análise nutricional, uma vez que este nutriente é bastante exportado em parte aérea corroborando com Gommers et al. (2005), que afirmam que o maior acúmulo de $\mathrm{K}$ nas plantas pode ser explicado em decorrência do fato de que, sob condições de alta disponibilidade de $\mathrm{K}$ no solo, onde as plantas absorvem quantidade acima da sua necessidade metabólica, ocorre o acúmulo deste nutriente em organelas da célula vegetal (como nos cloroplastos, nas mitocôndrias e, especialmente, nos vacúolos), caracterizando o "consumo de luxo". Os altos teores de Fe, Mn e Zn podem ser explicados pela elevada Cultura Agronômica, Ilha Solteira, v.26, n.3, p.265-284, 2017 
concentração inicial destes micronutrientes no solo, associado ao fato dos tratamentos com calcário líquido não terem reduzido a disponibilidade destes nutrientes.

Tabela 9. Teores médios de $\mathrm{N}, \mathrm{P}, \mathrm{K}, \mathrm{Ca}$ e $\mathrm{Mg}$ na raiz do feijoeiro em função de doses e fontes de corretivos. Ilha Solteira - SP, Brasil, 2014.

\begin{tabular}{|c|c|c|c|c|c|}
\hline \multirow[t]{2}{*}{ Doses $^{\#}$} & $\mathrm{~N}$ & $\mathrm{P}$ & $\mathrm{K}$ & $\mathrm{Ca}$ & $\mathrm{Mg}$ \\
\hline & \multicolumn{5}{|c|}{ 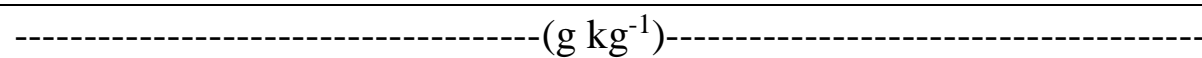 } \\
\hline 0 & 31,55 & 2,10 & 20,65 & 9,35 & 1,80 \\
\hline 0,5 & 27,95 & 2,23 & 21,13 & 10,18 & 1,98 \\
\hline 1 & 27,85 & 2,45 & 19,03 & 10,58 & 1,90 \\
\hline 2 & 31,03 & 2,13 & 20,30 & 9,63 & 1,88 \\
\hline
\end{tabular}

\section{Fontes}

\begin{tabular}{cccccc}
\hline Pó & $27,38 \mathrm{a}$ & $2,16 \mathrm{a}$ & $18,99 \mathrm{a}$ & $10,13 \mathrm{a}$ & $1,90 \mathrm{a}$ \\
Líquido & $31,81 \mathrm{a}$ & $2,29 \mathrm{a}$ & $21,56 \mathrm{a}$ & $9,74 \mathrm{a}$ & $1,88 \mathrm{a}$ \\
\hline D.M.S. (5\%) & 4,72 & 0,36 & 3,09 & 1,29 & 0,10 \\
Média Geral & 29,59 & 2,23 & 20,28 & 9,93 & 1,89 \\
C.V. (\%) & 13,50 & 13,56 & 12,90 & 11,03 & 4,48 \\
\hline
\end{tabular}

\# Doses 0; 0,5; 1 e 2 referem-se as doses aplicadas nos tratamentos, proporcionalmente, onde para o calcário em pó a dose 1 equivale à $2,5 \mathrm{t} \mathrm{ha}^{-1}$, e para o calcário líquido a dose 1 equivale à $5 \mathrm{~L}$ por tonelada de calcário em pó a ser aplicada.

Médias seguidas de mesma letra na coluna não diferem pelo teste de Tukey a 5\% de probabilidade.

Nas Tabelas 9 e 10 constam os teores de nutrientes (N, P, K, Ca, Mg, S, Cu, Fe, Mn e $\mathrm{Zn}$ na raiz do feijoeiro, sendo que semelhante ao observado na parte aérea, não houve efeito de doses e fontes de calcário, bem como da interação para os teores destes nutrientes na raiz do feijoeiro. Contudo, vale destacar que em relação à testemunha, em média, houve incrementos de 6,2; 26,1 e 6,6\% para os teores de P, S e Fe, respectivamente, com o aumento das doses de calcário. Por outro lado, o teor de $\mathrm{N}$ foi $6,2 \%$ inferior, em média, nos tratamentos que receberam a aplicação de calcário.

Comparativamente, os teores de $\mathrm{S}, \mathrm{Cu}, \mathrm{Fe}, \mathrm{Mn}$ e $\mathrm{Zn}$ na raiz foram superiores aos respectivos teores na parte aérea, possivelmente devido ao fato destes nutrientes já estarem em concentrações adequadas à alta na parte aérea do feijoeiro, ou seja, a maior concentração na raiz pode ser explicada pelo fato do feijoeiro estar bem suprido destes nutrientes, sendo assim, estes nutrientes poderiam estar no apoplasto da raiz. Diferentemente, Silva et al. (2007b) verificaram que os teores de $\mathrm{Zn}$, tanto no sistema radicular quanto na parte aérea, foram reduzidos com o incremento das doses de calcário, onde a redução na concentração de $\mathrm{Zn}$ nas raízes e na parte aérea das cultivares foi decorrente do aumento do $\mathrm{pH}$ e dos teores de $\mathrm{Ca}$, e, principalmente, de $\mathrm{Mg}$, que apresenta efeito competitivo com o $\mathrm{Zn}$ no solo (MALAVOTA, 1980). O efeito da calagem em diminuir a disponibilidade do $\mathrm{Zn}$ nos solos, e a sua absorção pelas plantas são muito conhecidos na literatura, embora não tenha sido verificado neste trabalho em função do $\mathrm{pH}$ inicial e dos altos teores de $\mathrm{Zn}$ do solo. As 
concentrações de zinco em raízes de diversas plantas variam de 60,0 a $185,0 \mathrm{mg} \mathrm{kg}^{-1}$ (OLIVEIRA; THUNG, 1988), sendo que, no presente trabalho os valores tanto da testemunha quanto dos demais tratamentos estão abaixo do supracitado.

Tabela 10. Teores médios de $\mathrm{S}, \mathrm{Cu}, \mathrm{Fe}, \mathrm{Mn}$ e $\mathrm{Zn}$ na raiz do feijoeiro em função de doses e fontes de calcário. Ilha Solteira-SP, Brasil, 2014.

\begin{tabular}{cccccc}
\hline Doses $^{\#}$ & $\mathrm{~S}$ & $\mathrm{Cu}$ & $\mathrm{Fe}$ & $\mathrm{Mn}$ & $\mathrm{Zn}$ \\
\hline & $\left(\mathrm{g} \mathrm{kg}^{-1}\right)$ & - & - & & \\
\hline 0 & 3,60 & 43,00 & 3539,5 & 123,0 & 58,00 \\
0,5 & 5,03 & 49,25 & 3309,5 & 224,8 & 75,25 \\
1 & 5,33 & 46,50 & 4485,5 & 189,5 & 59,00 \\
2 & 4,20 & 34,25 & 3764,5 & 160,8 & 65,00 \\
\hline Fontes & & & & & \\
\hline Pó & $4,64 \mathrm{a}$ & $43,38 \mathrm{a}$ & $4102,3 \mathrm{a}$ & $172,4 \mathrm{a}$ & $67,13 \mathrm{a}$ \\
Líquido & $4,44 \mathrm{a}$ & $43,13 \mathrm{a}$ & $3447,3 \mathrm{a}$ & $176,6 \mathrm{a}$ & $61,50 \mathrm{a}$ \\
\hline D.M.S. (5\%) & 1,66 & 12,81 & 709,0 & 73,3 & 11,18 \\
Média Geral & 4,54 & 43,25 & 3774,8 & 174,5 & 64,31 \\
C.V. (\%) & 30,92 & 25,06 & 15,89 & 35,53 & 14,71 \\
\hline
\end{tabular}

\# Doses 0; 0,5; 1 e 2 referem-se as doses aplicadas nos tratamentos, proporcionalmente, onde para o calcário em pó a dose 1 equivale à $2,5 \mathrm{t} \mathrm{ha}^{-1}$, e para o calcário líquido a dose 1 equivale à $5 \mathrm{~L}$ por tonelada de calcário em pó a ser aplicada.

Médias seguidas de mesma letra na coluna não diferem pelo teste de Tukey a 5\% de probabilidade.

Os teores de N, P, K, Ca e Mg foram inferiores aos teores de nutrientes na parte aérea, provavelmente devido a maior demanda destes macronutrientes para o metabolismo vegetal, uma vez que, a maior parte das reações metabólicas envolvendo nutrientes ocorrem nas folhas. Embora o Ca seja considerado imóvel na planta, uma das principais funções do cálcio é a na estrutura da planta, como integrante da parede celular, e sua deficiência afeta particularmente os pontos de crescimento da raiz, sendo também indispensável para a germinação do grão de pólen e crescimento do tubo polínico (PRADO, 2008), o que justifica sua concentração mais elevada na parte aérea do feijoeiro em pleno florescimento.

\section{CONCLUSÃO}

O calcário dolomítico propiciou menor acidez potencial e maiores teores de $\mathrm{Ca}$ e $\mathrm{Mg}$, $\mathrm{SB}, \mathrm{CTC}, \mathrm{pH}$ e V\%, indicando que o calcário líquido não foi eficaz na correção da acidez do solo e fornecimento de $\mathrm{Ca}$ e $\mathrm{Mg}$.

O aumento das doses de calcário dolomítico incrementou a SB, CTC, V\% e teores de $\mathrm{Ca}$ e $\mathrm{Mg}$ até valores próximos da dose de referência $\left(2,5 \mathrm{t} \mathrm{ha}^{-1}\right)$, reduziu a acidez potencial e aumentou o pH do solo até a dose de $2,7 \mathrm{tha}^{-1}$.

Cultura Agronômica, Ilha Solteira, v.26, n.3, p.265-284, 2017 
As fontes de calcário proporcionaram semelhantes teores de macronutrientes e de micronutrientes catiônicos tanto na parte aérea e como na raiz do feijoeiro irrigado.

Devido a fertilidade inicial do solo, o incremento das doses de calcário não influenciou nos teores de nutrientes do feijoeiro, independentemente da fonte de calcário.

\section{REFERÊNCIAS BIBLIOGRÁFICAS}

AMBROSANO, E. J.; TANAKA, R. T.; MASCARENHAS, H. A. A. Leguminosas e oleaginosas. In: VAN RAIJ, B.; CANTARELLA, H.; QUAGGIO, J. A.; FURLANI, A. M. C. (Ed.). Recomendações de adubação e calagem para o Estado de São Paulo. 2.ed. Campinas: IAC, 1997. p. 187-203. (Boletim Técnico 100)

ASSIS, R. T.; OLIVEIRA, I. J. V.; MORAIS, A. M. M.; NETO, A. A. M.; DIAS, S. H. Novas tecnologias para a agricultura brasileira. Araxá: Instituto de ciências da saúde, agrárias e humanas (ISAH), 2014. 7 p. (Circular Técnica, 02).

BARBOSA FILHO, M. P.; FAGERIA, N. K.; ZIMMERMANN, F. J. P. Atributos de fertilidade do solo e produtividade do feijoeiro e da soja influenciados pela calagem em superfície e incorporada. Ciência e Agrotecnologia, Lavras, v. 29, n. 3, p.507-514, 2005.

BINOTTI, F. F. S.; ARF, O.; CARDOSO, E. D.; SÁ, M. E.; BUZETTI, S.; NASCIMENTO, V. Fontes e doses de nitrogênio em cobertura no feijoeiro de inverno irrigado no sistema plantio direto. Bioscience Journal, Uberlândia, v. 26, n. 5, p.770-778, 2010 .

CAIRES, E. F.; BANZATTO, D. A.; FONSECA, A. F. Calagem na superfície em sistema plantio direto. Revista Brasileira de Ciência do Solo, Viçosa, v. 24, n. 1, p.161-169, 2000.

CALONEGO, J. C.; MORA, V. S.; SANTOS, C. H.; OLIVEIRA, L. Calagem e silicatagem em solo incubado com diferentes umidades. Colloquium Agrariae, Presidente Prudente, v. 8, n. 2, p.46-56, 2012.

CARDOZO, S. V.; PEREIRA, M. G.; RAVELLI, A.; LOSS, A. Caracterização de propriedades edáficas em áreas sob manejo orgânico e natural na região serrana do Estado do Rio de Janeiro. Semina: Ciências Agrárias, Londrina, v. 29, n. 3, p.517-530, 2008.

CHURKA BLUM, S.; CAIRES, E. F.; ALLEONI, L. R. F. Lime and phosphogypsum application and sulfate retention in subtropical soils under no-till system. Journal of Soil Science and Plant Nutrition, Temuco, v. 13, n. 2, p.279-300, 2013.

EMBRAPA - Empresa Brasileira de Pesquisa Agropecuária. Centro Nacional de Pesquisa de Solos. Sistema Brasileiro de Classificação de Solos. 3. ed. Brasília: EMBRAPA, 2013. $353 \mathrm{p}$.

FERREIRA, D. F. Sisvar: a computer statistical analysis system. Ciência e Agrotecnologia, Lavras, v. 35, n. 6, p.1039-1042, 2011.

Cultura Agronômica, Ilha Solteira, v.26, n.3, p.265-284, 2017 
GALINDO, F. S.; TEIXEIRA FILHO, M. C. M; BUZETTI, S.; SANTINI J. M. K.; BELlotTE, J. L. M.; LUDKIEWICZ, M. G. Z.; ANDREOTTI, M.; SILVA, V. M.; GARCIA, C. M. P. Atributos químicos do solo após cultivo de trigo sob adubação nitrogenada e inoculação com Azospirillum brasilense. Semina: Ciências Agrárias, Londrina, v. 38, n. 2, p.659-670, 2017.

GOMMERS, A.; THIRY, Y.; DELVAUX, B. Rhizospheric mobilization and plant uptake of radiocesium from weathered soils: I. Influence of potassium depletion. Journal of Environmental Quality, Madison, v. 34, n. 6, p.2167-2173, 2005.

LEITE, G. H. M. N.; ELTZ, F. L. F.; AMADO, T. J. C.; COGO, N. P. Atributos químicos e perfil de enraizamento de milho influenciados pela calagem em semeadura direta. Revista Brasileira de Ciência do Solo, Viçosa, v. 30, n. 4, p.685-693, 2006.

MALAVOLTA, E. Elementos de nutrição mineral de plantas. São Paulo: Agronômica Ceres, 1980. $256 \mathrm{p}$.

MALAVOLTA, E.; VITTI, G. C.; OLIVEIRA, A. S. Avaliação do estado nutricional das plantas: Princípios e aplicações. Piracicaba: Associação Brasileira para Pesquisa da Potassa e do Fósforo, 1997. 319 p.

MATTIELlO, E. M.; PEREIRA, M. G.; ZONTA, E. Efeito da calagem nas propriedades químicas de um Organossolo e no conteúdo de nutrientes da fitomassa do feijoeiro (Phaseolus vulgaris L. Cv.carioca). Revista Universidade Rural, Série Ciências da Vida, Seropédica, v. 26, n. 1, p.51-56, 2006.

MELLO, J. C. A.; VILlAS BOAS, R. L.; LIMA, E. V.; CRUSCIOL, C. A. C.; BULL, L. T. Alterações nos atributos químicos de um Latossolo distroférrico decorrentes da granulometria e das doses de calcário em sistema plantio direto e convencional. Revista Brasileira de Ciência do Solo, Viçosa, v. 27, n. 3, p.553-561, 2003.

NASCENTE, A. S.; COBUCCI, T. Calcário na forma de micropartículas aplicado no sulco de semeadura aumenta produtividade do feijoeiro. Revista Ceres, Viçosa, v. 62, n. 6, p.597606, 2015.

NICOLODI, M.; ANGHINONI, I.; GIANELLO, C. Relações entre os tipos e indicadores de acidez do solo em lavouras no sistema plantio direto na região do Planalto do Rio Grande do Sul. Revista Brasileira de Ciência do Solo, Viçosa, v. 32, n. 3, p.1217-1226, 2008.

NÓIA, N. R. C.; CRUZ, M. C. P.; DAVALO, M. J.; OLIVEIRA, M. C.; FUJITA, C. K. Produção de matéria seca de alfafa (Medicago sativa L.) em função de doses de calcário. Científica, Jaboticabal, v. 42, n. 3, p.310-315, 2014.

OLIVEIRA, I. P.; THUNG, M. D. T. Nutrição mineral. In: ZIMMERMANN, M. J. O.; ROCHA, M.; YAMADA, T. Cultura do feijoeiro: fatores que afetam a produtividade. Piracicaba: POTAFÓS, 1988. p. 185-212.

Cultura Agronômica, Ilha Solteira, v.26, n.3, p.265-284, 2017 
PENDIAS, A. K.; PENDIAS, H. Trace elements in soil and plants. Boca Raton: CRC, 1984. $315 \mathrm{p}$.

PRADO, R. M. Nutrição de plantas. São Paulo: Editora UNESP, 2008. 407 p.

RAIJ, B. Van. Acidez e Calagem. In: VALE, D. W.; SOUSA, J. I.; PRADO, R. M. Manejo da fertilidade do solo e nutrição de plantas. Jaboticabal: FCAV, 2010. cap. 3, p.37-68.

RAIJ, B. Van; ANDRADE, J. C.; CANTARELlA, H.; QUAGGIO, J. A. Análises químicas para avaliação da fertilidade de solos tropicais. Campinas: Instituto Agronômico, 2001. 285 p.

RAIJ, B. Van; CANTAREllA, H.; QUAGGIO, J. A.; FURLANI, A. M. C. Recomendações de calagem e adubação para o Estado de São Paulo. Campinas: Instituto Agronômico de Campinas, 1997. 285 p. (Boletim técnico, 100).

RANGEL, A. F.; RAO, I. M.; HORST, W. J. Intracellular distribution and binding state of aluminum in root apices of two common bean (Phaseolus vulgaris) genotypes in relation to Altoxicity. Physiologia Plantarum, Helsinki, v. 135, n. 2, p.162-173, 2009.

ROSSIELO, R.O.P.; JACOB NETO, J. Toxidez de aluminio em plantas: novos enfoques para um velho problema. In: FERNANDES, M.S. (Ed.). Nutrição mineral de plantas. Viçosa: Sociedade Brasileira de Ciência do Solo, 2006. cap. 15, p. 375-418.

SCHUlTZ, N.; LOSS, A.; PEREIRA, M. G.; BEUTLER, S. J.; ZONTA, E. Desenvolvimento de feijoeiro comum cultivado em amostras de Organossolo com diferentes níveis de calagem. Revista Ciência Agronômica, Fortaleza, v. 42, n. 2, p.285-291, 2011.

SILVA, L. M.; LEMOS, L. B.; CRUSCIOL, C. A. C.; MATEUS, G. P.; FELTRAN, J. C. Eficiência de utilização de nutrientes em cultivares de feijão em razão da calagem. Revista de Agricultura, Piracicaba, v. 82, n. 2, p.184-196, 2007a.

SILVA, L. M.; LEMOS, L. B.; CRUSCIOL, C. A. C.; MATEUS, G. P.; FELTRAN, J. C. Crescimento radicular e absorção de micronutrientes do feijoeiro em razão da calagem. Científica, Jaboticabal, v. 35, n. 2, p.88-105, 2007 b.

SILVA, T. R. B.; LEMOS, L. B.; CRUSCIOL, C. A. C.; FIORENTIN, C. F. Resposta de cultivares de feijoeiro comum à calagem superficial em semeadura direta. Semina: Ciências Agrárias, Londrina, v. 33, n. 4, p.1281-1290, 2012.

SILVA, E. B; SILVA, A. C.; GRAZZIOTTI, P. H; FARNEZI, M. M. M.; FERREIRA, C. A.; COSTA, H. A. O.; HORAK, I. Comparação de método para estimar a acidez potencial mediante determinação do pH SMP em ORGANOSSOLOS da Serra do Espinhaço Meridional. Revista Brasileira de Ciências do Solo, Viçosa, v. 32, n. 5, p.2007-2013, 2008

SOUSA, L. F. R. A.; MARINHO, R. W. D.; NUNES, F. M.; SILVA, R. V.; NASCIMENTO, I. O.; SILVA, W. A. da. Determinação do pH de um Argissolo Vermelho

Cultura Agronômica, Ilha Solteira, v.26, n.3, p.265-284, 2017 
Amarelo distrófico incubado com aplicação de doses crescentes de $\mathrm{CaCo}_{3}$ por diferentes métodos. Revista Agroecossistemas, Belém, v. 5, n. 2, p.58-63, 2013.

SOUZA, H. A.; NATALE, W.; ROZANE, D. E.; HERNANDES, A.; ROMUALDO, L. M. Calagem e adubação boratada na produção de feijoeiro. Revista Ciência Agronômica, Fortaleza, v. 42, n. 2, p.249-257, 2011. 